\title{
Electrocardiographic localization of infarct related coronary artery in acute inferior wall ST elevation myocardial infraction and in hospital outcome in tertiary cardiac care center
}

\author{
Rajaram Khanal, Arun Sayami, Ratnamani Gajurel, Hemanta Shrestha, Sanjeev Thapa, Ravi Sahi
}

Department of Cardiology, Manmohan Cardio Vascular Thoracic and Transplant Centre (MCVTC)

Correspoding Author: Raja Ram Khanal

Department of Cardiology, Manmohan Cardio Vascular Thoracic and Transplant Centre (MCVTC), Institute of Medicine, TUTH, Nepal. E-mail: khanalr82@gmail.com

\section{Abstract}

Background: In addition to diagnosing the acute ST Elevation MI stratifying (STEMI) high-risk patients and proper treatment strategies are important issues in managing patients. The goal of this study was to determine the relation of ST segment changes in Electrocardigram with the site of occlusion in vessel, to evaluate the prognostic value of ST segment deviation in aVR and its role in identification of Infarct Related Artery (IRA) in patients with acute inferior myocardial infarction.

Methods: The study included 56 patients with acute inferior wall STEMI. All patients underwent Coronary Angiogram. Patients were divided into two groups based on the IRA and were followed up during their hospital stay for complications.

Result: The culprit artery was Right Coronary Artery (RCA) in 40 patients (71.4\%) and Left Circumflex Artery (LCX) in 13 patients $(23.2 \%)$. Study showed $92 \%$ sensitivity, $80 \%$ specificity for predicting RCA related infarction with ST elevation lead III > lead II and $83 \%$ sensitivity, $90 \%$ specificity for (LCX) with ST elevation lead II > lead III . The overall in-hospital mortality was $3.5 \%$.

ST depression in aVR was associated with $87.5 \%$ specificity and $83 \%$ sensitivity in diagnosing LCX as the Infarct Related Artery (IRA). The in-hospital mortality rates for patients with ST segment deviation in aVR (20 patients) and no ST segment changes (36 patients) were $5 \%$ and $2.7 \%$ respectively.

Conclusion: In addition to the conventional ECG criteria for identifying culprit vessel, lead aVR may be useful in clinical practice when assessing patients with inferior STEMI and with poor in-hospital outcome.

Key Words: aVR, Coronary angiography, Infarct Related Artery, Inferior STEMI.

DOI: http://dx.doi.org/10.3126/njh.v15i1.19712

\section{Introduction}

Various ECG criteria have been suggested to predict the culprit artery based on analysis of ST-segment elevation and depression in different leads ${ }^{1-3}$. More recently, ST-segment depression in lead aVR has been suggested as a predictor of Left Circumflex Artery (LCX) involvement ${ }^{4-6}$. aVR depression was also shown to be associated with significantly impaired myocardial perfusion $^{(7)}$. Predicting the culprit artery in inferior STEMI can be challenging as the dominance of the Right Coronary Artery (RCA) and LCX can vary significantly among patients.

Stenosis of the proximal portion of RCA and RV involvement may cause $\mathrm{RV}$ failure and poor prognosis ${ }^{8}$. Considerable numbers of patients with highly suspected MI have normal on admission ECG, hence serial ECGs and also additional (right and posterior leads) may help physicians to deal with such cases?.

Here we focused on different ECG pre-specified criteria for prediction of occluded vessel in acute inferior wall STEMI and role of lead aVR in identifying of Infarct Related Artery.

\section{Methods}

The study included 56 patients who were admitted to Manmohan Cardio Vascular Thoracic Centre (MCVTC), with diagnosis of acute inferior wall ST elevation myocardial infarction

Patients who met the following criteria were included in the study:

1. Anginal chest pain lasting for more than 30 minutes

2. ST elevation more than $1 \mathrm{~mm}$ in leads II ,III, aVF

3. Who underwent coronary angiography during hospitalization, where the infarct related artery was confirmed.

Patients with the following conditions were excluded from the study

1. with previous history of acute myocardial infarction, CABG, PCI prior to the current hospitalization

2. Significant stenosis in both RCA and LCX so that the single infarct related artery could not be defined 
A total of 56 patients who met the inclusion criteria were enrolled in the study. Forty patients underwent primary PCI and one patient received thrombolytic therapy in other centre. Admission ECG was recorded and analyzed. Left ventricular ejection fraction was estimated with transthoracic echocardiogram using Simpson's method. Coronary angiography was done for all patients during primary and elective Percutaneous Coronary Intervention (PCI). As per ADA criteria for the diagnosis of Diabetes Mellitus (DM), $\mathrm{JNC}^{8}$ for Hypertension (HTN), 2013 ACC/AHA guideline for Dyslipidimea and World Health Organization (WHO) definition for smoking were used.

\section{ECG analysis:}

Standard 12 lead electrocardiograms were recorded at a speed of $25 \mathrm{~mm} / \mathrm{s}$ and voltage of $10 \mathrm{~mm} / \mathrm{mV}$.The TP segment was used as the isoelectric line. The following findings were identified.

1. ST elevation in lead II and III

2. ST elevation in lead I, aVL, V5.V6

3. ST elevation in lead $\mathrm{V} 1$ and $\mathrm{V} 4 \mathrm{R}$

4. ST depression in lead I,aVL, V1,V2, V3

5. ST depression in lead aVR

6. Sum of ST depression of V1 to V3 divided by ST elevation of II, III, aVF

\section{Coronary Angiography(CAG):}

CAG was performed in all patients. The Infarct related artery was identified by either Total occlusion or a significant stenosis $(>70 \%)$ of the RCA or LCX or their major branches. Criteria for single vessel and others, is defined with more than $50 \%$ lesion in major epicardial artery

All patients were followed up during their hospital stay. The presence of a second, third degree atrioventricular block, sustained ventricular tachycardia, ventricular fibrillation was noted. Death and cardiogenic shock were recorded.

The heart failure was diagnosed based on the presence of pulmonary rales, pulmonary edema, $\mathrm{X}$ ray chest or third heart sound.

\section{Statistical Analysis:}

All statistical analysis was performed using SPSS. Categorical data were analyzed in terms of frequency and continuous data presented as means $\pm \mathrm{SD}$.

Dichotomous variables were compared by Chi- square test and independent samples $t$ test used to compare means of continuous variables. The sensitivity and specificity of ECG findings to predict the culprit artery were calculated.

\section{Results}

The mean age of the patients was $59.11 \pm 11$ years with $73 \%$ male. The youngest patient was a 36 year-old man and the oldest was a 84 year-old women. Among male patients $31.7 \%$ were diabetics and among female patients $26.6 \%$ were diabetics. (P value:0.716) 14 patients (25\%) had a single vessel disease, 19 patients (34\%) double vessel disease and 23 patients(41\%) had a triple vessel disease: $50 \%$ of the patients with diabetes had Triple vessel disease.

\begin{tabular}{|c|c|c|}
\hline \multicolumn{2}{|l|}{$\begin{array}{l}\text { lable 1: B } \\
\text { Variables }\end{array}$} & No: 56 \\
\hline \multicolumn{2}{|l|}{ Male } & Age: $57.59 \pm 10.96$ \\
\hline \multicolumn{2}{|l|}{ Female } & Age: $63.35 \pm 10.34$ \\
\hline \multicolumn{2}{|l|}{$\mathrm{DM}$} & $17(30.3 \%)$ \\
\hline \multicolumn{2}{|l|}{ HTN } & $24(42.8 \%)$ \\
\hline \multicolumn{2}{|l|}{ Smoking } & $36(64.2 \%)$ \\
\hline \multicolumn{2}{|l|}{ Dyslipidemia } & $6(10.7 \%)$ \\
\hline \multicolumn{2}{|l|}{ Family history } & $3(5.3 \%)$ \\
\hline \multirow[t]{4}{*}{ Killip Class } & I & $37(66 \%)$ \\
\hline & II & $12(21.4 \%)$ \\
\hline & III & $3(5.3 \%)$ \\
\hline & IV & $4(7.1 \%)$ \\
\hline \multicolumn{2}{|l|}{ CPK-MB } & $70.09 \pm 82.07$ \\
\hline \multicolumn{2}{|l|}{ Troponin I } & $7.5 \pm 17.32$ \\
\hline \multicolumn{2}{|l|}{ Primary PCI } & $40(71.4 \%)$ \\
\hline \multicolumn{2}{|l|}{ Thrombolysis } & $1(1.7 \%)$ \\
\hline \multirow[t]{3}{*}{ LV EF: } & Normal & $30(53.5 \%)$ \\
\hline & Mild LVSD & $21(37.5 \%)$ \\
\hline & Moderate LVSD & $5(8.9 \%)$ \\
\hline
\end{tabular}

The culprit artery was found to be the RCA in 40 patients (71.4\%) and the LCX in 13 patients (23.2\%). In remaining three patients the culprit arteries were Ramus intermedius 2 patient \& LAD 1 patient. The baseline clinical characteristics are shown in Table1 and the angiographic data of all patients are displayed in Table2. The 25 patients (44.6\%) with inferior wall myocardial infarction had right ventricular infarct and 6 patients $(10.7 \%)$ had posterior wall involvement. In the RCA group 14 Patients(35\%) had ST elevation in lead V1 and 1 Patient $(7.7 \%)$ in the LCX group.

Table 2: IRA(Infarct-related artery) based on angiography

\begin{tabular}{|l|c|}
\hline Culprit artery & $\begin{array}{l}\text { Distribution (\% of the total } \\
\text { sample size) }\end{array}$ \\
\hline RCA (Right coronary artery) & $40(71.4 \%)$ \\
\hline Proximal & $19(33.9 \%)$ \\
\hline Middle & $11(19.6 \%)$ \\
\hline Distal & $10(17.8 \%)$ \\
\hline LCX (Left circumflex artery) & $13(23.2 \%)$ \\
\hline Proximal & $6(10.7 \%)$ \\
\hline Non proximal & $4(7.1 \%)$ \\
\hline Obtuse marginal & $3(5.3 \%)$ \\
\hline $\begin{array}{l}\text { LAD (Left anterior } \\
\text { descending artery) }\end{array}$ & $1(1.7 \%)$ \\
\hline RI (Ramus Intermedius) & $2(3.5 \%)$ \\
\hline
\end{tabular}


ST depression in lead aVR was found in 10 patients (77\%) with LCX related infarction and in 5patients (12\%) with RCA related infarction(P-value: $<0.001) 24$ patients $(60 \%)$ in the RCA group had ST elevation in lead V4R and 1patient (7.7\%) in the LCX group.

\section{RCA as the culprit artery:}

The value of the ECG criteria and lead aVR in diagnosing RCA or LCX as the culprit artery is listed in table 3 and 4 . With RCA related infarct, a greater ST elevation in lead III than in lead II (Figure 1) had sensitivity of $92 \%$ and specificity of $80 \%$. A high sensitivity $92 \%$ and low specificity $45 \%$ were identified when Sum of ST depressions of V1to V3 divided by sum of ST elevation of inferior leads is $\leq 1$. ST elevation in lead V4R had sensitivity of $81 \%$ and specificity of $45 \%$ for proximal RCA lesion.

\begin{tabular}{|c|c|c|}
\hline ST segment deviation & Sensitivity & Specificity \\
\hline \multicolumn{3}{|l|}{ RCA: } \\
\hline Elevation in lead III >II & $92 \%$ & $80 \%$ \\
\hline Elevation in lead V4R & $81.25 \%$ & $45 \%$ \\
\hline Depression aVL > I & $70.25 \%$ & $53.3 \%$ \\
\hline $\begin{array}{l}\text { Sum of depressions of V1 } \\
\text { to V3 Divided by sum of } \\
\text { elevations of inferior leads } \leq 1\end{array}$ & $92.1 \%$ & $45 \%$ \\
\hline
\end{tabular}

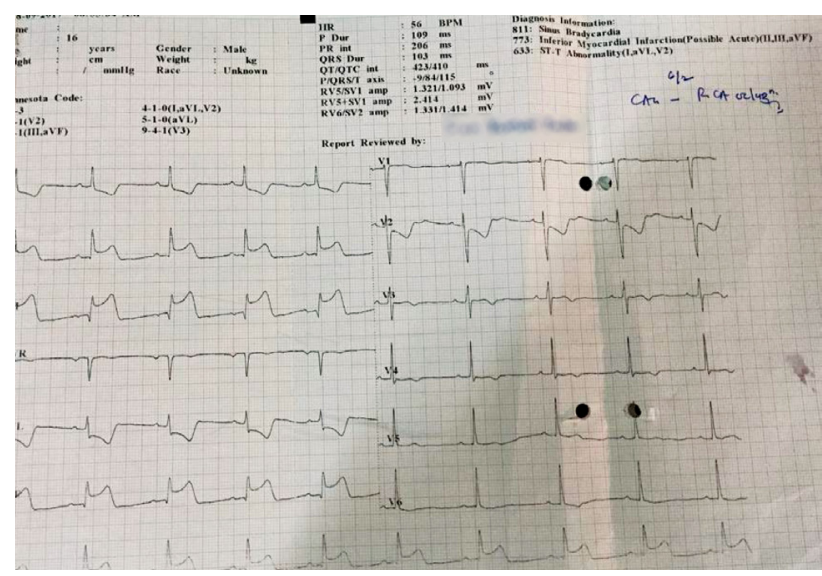

Figure 1: ST elevation III $>I I$

\section{LCX as the culprit artery:}

With LCX related infarct, a greater ST elevation in lead II than in lead III (Figure 2) had a sensitivity of $83 \%$ and specificity of $90 \%$. ST depression in lead aVR was associated with $83 \%$ sensitivity and $87.5 \%$ specificity in diagnosing LCX. The ST elevation in lead I was associated with high specificity 97\% in diagnosing LCX involvement.

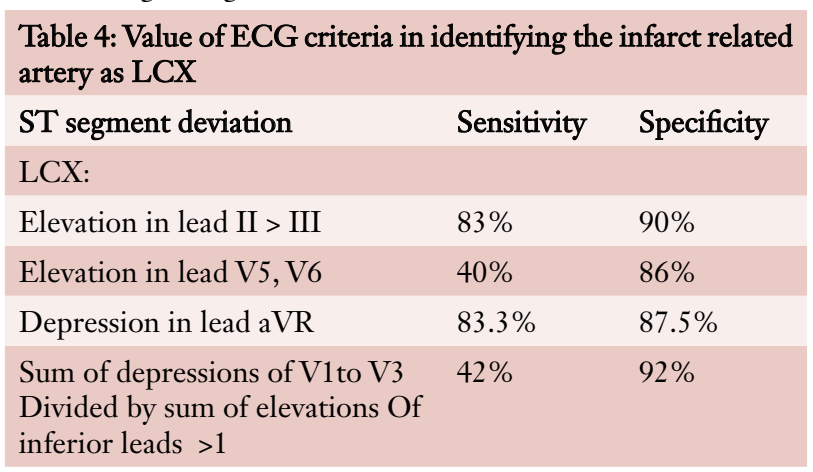

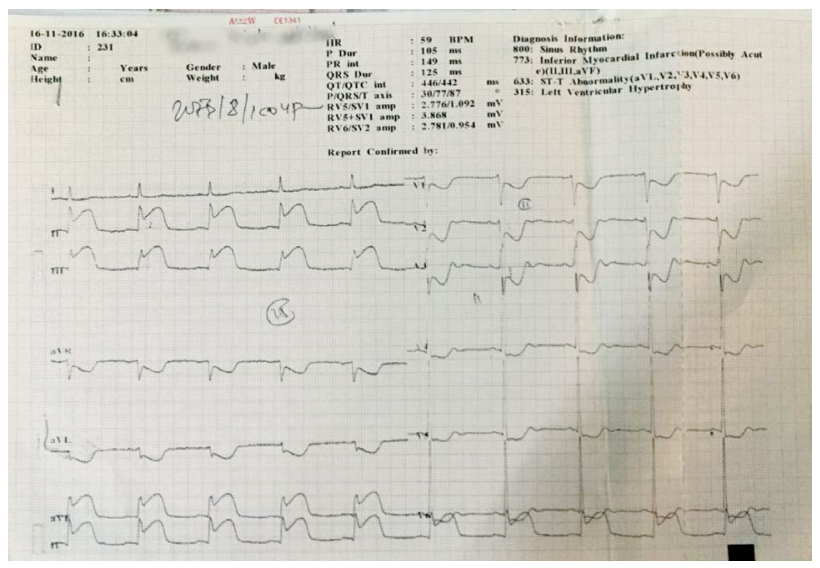

Figure 2 : ST elevation $I I>I I I$

\section{In-Hospital outcome}

During hospitalization 4 patients $(7.1 \%)$ were in cardiogenic shock and 10 patients (17.8\%) had second or third degree AV block. The in-hospitality mortality was in 2 patients (3.5\%). One patient died due to cardiogenic shock and another patient due to refractory ventricular arrhythmia. The in hospital outcomes of the patients is shown in table 5 .

\begin{tabular}{|ll|}
\hline Table 5: In Hospital outcomes & \\
\hline Variables & Distribution \\
\hline Cardiogenic shock & $4(7.1 \%)$ \\
\hline 2nd, 3rd AV Block : & $10(17.8 \%)$ \\
\hline VT/VF & $6(10.7 \%)$ \\
\hline Sinus Bradycardia requiring TPI & $3(5.3 \%)$ \\
\hline AF & $2(3.5 \%)$ \\
\hline Post MI pericarditis: & $2(3.5 \%)$ \\
\hline Post MI pericardial effusion: & $1(1.7 \%)$ \\
\hline CPR & $4(7.1 \%)$ \\
\hline Death & $2(3.5 \%)$ \\
\hline
\end{tabular}

In order to assess the prognostic value of ST-segment deviation in lead aVR,(Shown in table 6) patients were re-divided according to the presence or absence of ST-segment deviation (elevation or depression) in lead aVR. Arrhythmic events, namely AV-block or VF/VT, were comparable in both groups. aVR

Table 6: Prognostic value of ST segment deviation in lead

\begin{tabular}{|lccr|} 
Complications & $\begin{array}{l}\text { ST-segment } \\
\text { Deviated in aVR } \\
\text { (20 patients) }\end{array}$ & $\begin{array}{l}\text { ST-segments } \\
\text { isoelectric in aVR } \\
\text { (36 patients) }\end{array}$ & P-value \\
\hline $\begin{array}{l}\text { In hospital } \\
\text { mortality }\end{array}$ & $1(5 \%)$ & $1(2.7 \%)$ & 1.00 \\
\hline AV block & $3(15 \%)$ & $7(19.4 \%)$ & 1.00 \\
\hline VT/NF & $3(15 \%)$ & $3(8.3 \%)$ & 0.65 \\
\hline AF & $2(10 \%)$ & $0(0 \%)$ & 0.12 \\
\hline
\end{tabular}

\section{Discussion}

In STEMI the time of blood flow reestablishment in infarct area is crucial. Immediate and accurate stratification of high-risk patients is also important in this situation. Identifying the culprit artery on presenting ECG can lead to earlier risk stratification and better guidance of therapy for reperfusion. The culprit artery 
Electrocardiographic localization of infarct related coronary artery in acute inferior wall ST elevation myocardial infraction and in hospital outcome in tertiary cardiac care center

of anterior STEMI is nearly always the left anterior descending artery, but inferior STEMI can be caused by an occlusion of either the right coronary artery (RCA) or left circumflex artery (LCX).

The RCA supplies blood mainly to the inferior myocardium, whereas the LCX supplies blood to the posterior, posterolateral, or posteroinferior myocardium ${ }^{10}$. This study found that in patients with inferior STEMI, the RCA is much more likely than the LCX to be the culprit artery, with a ratio of $3: 1$. These results are consistent with previous other studies by where the RCA to LCX ratio was found to vary from 2.2:1 to 7.0:1 ${ }^{11-15}$

The diagnostic value of the different ECG criteria was assessed in this study as mentioned in (Table 2 and 3). In most patients with RCA occlusion the current of injury will be reflected more in lead III than in lead II. Conversely, with LCX occlusion the current of injury will be seen more in lead II than in lead III ${ }^{11}$. Walid Elhammady found that ST elevation in lead III > II for RCA lesion had sensitivity and specificity of $92 \%$ and $78 \%$ respectively and for LCX lesion, lead II >III with sensitivity and specificity of $80 \%$ and $93 \%$ respectively ${ }^{16}$. The reported sensitivity and specificity of Fiol et $\mathrm{al}^{17}$ study, for RCA prediction, were $96 \%$ and $38 \%$ respectively. Various ECG findings have been evaluated to differentiate the culprit artery in acute inferior wall STEMI. Still, there is a small portion of patients whose culprit artery can not be accurately identified by these criteria. In our study 2 patients had involvement of Ramus Intermedius as the culprit artery and 1 patient with LAD as the culprit artery.

The important finding of our study is that aVR depression represents myocardial infarction involving the LCX artery with good sensitivity and specificity. In our study ST depression in lead aVR was in $77 \%$ of the LCX group with sensitivity and specificify of $83.3 \%$ and $87.5 \%$ respectively.

Sun et al. ${ }^{18}$ found that ST depression in aVR was found in $70 \%$ of patients who had LCX as the infarct related artery with sensitivity and specificity of $70.0 \%$ and $94.3 \%$, respectively. Walid Elhammady found that ST depression in aVR was found in $85 \%$ who had LCX as the culprit artery with sensitivity and specificity of $86 \%$ and $92 \%$ respectively ${ }^{16}$. In RCA occlusion, the injury vector is toward the right side and results in ST depression in leads I and aVL. ${ }^{19}$. To define the proximal occlusion of RCA, Fiol et $\mathrm{al}^{20}$ proposed aVL depression $\geq$ lead I depression as a criterion. In our study ST depression in lead aVL $>$ I for proximal RCA occlusion had sensitivity and specificity of $70 \%$ and $53 \%$.

The ST segment elevation in V4R (occluded before right ventricular branch) is useful for identifying occlusion of RCA. Occlusion of proximal-RCA in right dominant hearts, led to ST elevation of right precordial leads due to RV involvement ${ }^{21}$. In our study the sensitivity and specificity of ST elevation in V4R for proximal RCA was $81 \%$ and $45 \%$ respectively.

The in-hospital mortality in our study was 3.6\%. In the study conducted by Walid Elhammady, the in hospital mortality was $5 \%{ }^{16}$. In the study conducted by Malla RR et al the in-hospital mortality in patients with inferior wall myocardial infarction was $5.6 \%{ }^{22}$ In the present study it was observed that higher rates of death $(6.6 \%$ vs. $2.4 \%$,$) and arrhythmia in patients with ST$ segment deviation compared to patients with no ST segment changes. Similar results were observed in the study conducted by Walid Elhammady ${ }^{16}$. These findings were supported by Kukla et al..$^{23}$ findings, who stated that ST segment changes in lead aVR occurred in approximately half of inferior wall STEMI patients. The presence of such ST segment changes was associated with a poorer prognosis during the hospital stay. From the present study it was shown that patients with ST segment deviation in aVR were at a higher risk.

\section{Limitation of the study:}

This study has a small sample size and was a single center study.

\section{Conclusion:}

The present study showed that lead aVR which is neglected is useful in clinical practice when assessing patients with inferior STEMI as the presence of ST segment depression in aVR suggests a LCX infarction with good sensitivity and specificity. In addition, ST segment deviation in aVR was associated with poor in-hospital outcome.

\section{References}

1. Kosuge $M$, Kimura $\mathrm{K}$, Ishikawa $\mathrm{T}$, et al. New electrocardiographic criteria for predicting the site of coronary artery occlusion in inferior wall acute myocardial infarction. Am J Cardiol 1998; 82(11): 1318-22. https://doi. org/10.1016/S0002-9149(98)00634-1

2. Fiol M, Cygankiewicz I, Carrillo A, et al. Value of electrocardiographic algorithm based on "ups and downs" of ST in assessment of a culprit artery in evolving inferior wall acute myocardial infarction. Am J Cardiol 2004; 94(6):70914. https://doi.org/10.1016/j.amjcard.2004.05.053

3. Tierala I, Nikus KC, Sclarovsky S, et al. Predicting the culprit artery in acute ST-elevation myocardial infarction and introducing a new algorithm to predict infarct-related artery in inferior ST-elevation myocardial infarction: Correlation with coronary anatomy in the HAAMU Trial. J Electrocardiol 2009; 42(2):120-7. https://doi.org/10.1016/j. jelectrocard.2008.12.009

4. Menown IBA, Adgey AAJ. Improving the ECG classification of inferior and lateral myocardial infarction by inversion of lead aVR. Heart 2000; 83(6):657-60. https://doi.org/10.1136/ heart.83.6.657

5. Nair R, Glancy DL. ECG discrimination between right and left circumflex coronary arterial occlusion in patients with acute inferior myocardial infarction: Value of old criteria and use of lead aVR. Chest 2002; 122(1):134-9. https://doi. org/10.1378/chest.122.1.134

6. Sun TW, Wang LX, Zhang YZ. The value of ECG lead aVR in the differential diagnosis of acute inferior wall myocardial infarction. Intern Med 2007; 46(12):795-9. https://doi. org/10.2169/internalmedicine.46.6411

7. Kosuge U, Kimura K, Ishikawa T, et al. ST-segment depression in lead aVR: A useful predictor of impaired myocardial reperfusion in patients with inferior acute myocardial infarction. Chest 2005; 128(2):780-6. https://doi. org/10.1378/chest.128.2.780

8. Braat SH, De Zwaan C, Brugada P, Coenegracht JM, Wellens HJ. Right ventricular involvement with acute inferior wall myocardial infarction identifies high risk of developing atrioventricular nodal conduction disturbances. Am Heart J 1984; 107:1183-1187. https://doi.org/10.1016/00028703(84)90275-8

9. Aqel RA, Hage FG, Ellipeddi P, Blackmon L, McElderry HT, Kay GN, et al. Usefulness of three posterior chest leads for the detection of posterior wall acute myocardial infarction. Am J Cardiol 2009 Jan 15;103(2):159-64. https://doi. org/10.1016/j.amjcard.2008.09.008

10. Zhong Qun Z, Wei W, Shu Yi D, et al. Electrocardiographic characteristics in angiographically documented occlusion of the dominant left circumflex artery with acute inferior myocardial infarction: Limitations of ST elevation 
III/II ratio and ST deviation in lateral limb leads. J Electrocardiol 2009; 42(5):432-9. https://doi.org/10.1016/j. jelectrocard.2009.03.015

11. Chia BL, Yip JWL, Tan HC, et al. Usefulness of ST elevation II/ III ratio and ST deviation in lead I for identifying the culprit artery in inferior wall acute myocardial infarction. Am J Cardiol 2000; 86(3):341-3. https://doi.org/10.1016/S00029149(00)00929-2

12. Kühl JT, Berg RMG. Utility of lead aVR for identifying the culprit lesion in acute myocardial infarction. Ann Noninvas Electrocardiol 2009; 14(3):219-25. https://doi.org/10.1111/ j.1542-474X.2009.00300.x

13. Zimetbaum PJ, Krishnan S, Gold A, et al. Usefulness of ST-segment elevation in Lead III exceeding that of lead II for identifying the location of the totally occluded coronary artery in inferior wall myocardial infarction. Am J Cardiol 1998; 81(7):918-9. https://doi.org/10.1016/S00029149(98)00013-7

14. Herz I, Assali AR, Adler Y, et al. New electrocardiographic criteria for predicting either the right or left circumflex artery as the culprit coronary artery in inferior wall acute myocardial infarction. Am J Cardiol 1997; 80(10):1343-5. https://doi.org/10.1016/S0002-9149(97)00678-4

15. Bayram E, Atalay C. Identification of the culprit artery involved in inferior wall acute myocardial infarction using electrocardiographic criteria. J Int Med Res 2004; 32(1):3944. https://doi.org/10.1177/147323000403200106

16. Walid Elhammady, aVRThe Neglected Electrocardiographic Lead: Diagnostic and Prognostic Value in Inferior STElevation Myocardial Infarction Heart Mirror Journal From Affiliated Egyptian Universities and Cardiology Centers Vol. 7, No. 1, 2013 ISSN 1687-6652

17. Fiol M, Cygankiewicz I, Carrillo A, Bayes-Genis A, Santoyo $\mathrm{O}$, Gomez A, et al. Value of electrocardiographic algorithm based on 'ups and downs' of ST in assessment of a culprit artery in evolving inferior wall acute myocardial infarction Am J Cardiol. 2004; 94:709-714. https://doi.org/10.1016/j. amjcard.2004.05.053

18. Sun TW, Wang LX, Zhang YZ. The value of ECG lead aVR in the differential diagnosis of acute inferior wall myocardial infarction. Intern Med 2007; 46(12):795-9. https://doi. org/10.2169/internalmedicine.46.6411

19. . Hira RS, Wilson JM, Birnbaum Y. Introducing a new algorithm in inferior ST-segment elevation myocardial infarction to predict the culprit artery and distinguish proximal versus distal lesions. Coronary Artery Disease 2011, 22:16517013. https://doi.org/10.1097/MCA.0b013e328342c748

20. Fiol M, Carrillo A, Cygankiewicz I, Ayestarán J, Caldés O, Peral V, et al. New criteria based on ST changes in 12-lead surface ECG to detect proximal versus distal right coronary artery occlusion in a case of acuteinferoposterior myocardial infarction. Ann Noninvasive Electrocardiol. 2004 (4):383-8 https://doi.org/10.1111/j.1542-474X.2004.94585.x

21. Kosuge M, Kimura K, Ishikawa T, Hongo Y, Shigemasa T, Sugiyama M, et al. Implications of the absence of ST-segment elevation in lead V4R in patients who have inferior wall acute myocardial infarction with right ventricular involvement. Clin- Cardiol. 2001 (3):225-30.

22. Malla RR, Sayami A.In hospital complications and mortality of patients of inferior wall myocardial infarction with right ventricular infarction. JNMA J Nepal Med Assoc. 2007 ;46(167):99-102.

23. Kukla P, Bryniarski L, Dudek D, et al. Prognostic significance of ST segment changes in lead aVR in patients with acute inferior myocardial infarction with ST segment elevation. Kardiol Pol 2012; 70(2):111-8.
Cite this article as: Rajaram Khanal, Arun Sayami, Ratna Mani Gajurel et.al. Electrocardiographic localization of infarct related coronary artery in acute inferior wall ST elevation myocardial infraction and in hospital outcome in tertiary cardiac care center. Nepalese Heart Journal 2018; 15(1): 23-27. http://dx.doi.org/10.3126/njh.v15i1.19712 